\title{
Adropin inhibited tilapia hepatic glucose output and triglyceride accumulation via AMPK activation
}

\author{
Chaoyi Zhang, Qianli Zhang, Zhihong Huang and Quan Jiang \\ Key Laboratory of Bio-Resource and Eco-Environment of Ministry of Education, College of Life Sciences, Sichuan University, Chengdu, China \\ Correspondence should be addressed to Q Jiang; jiangqua@gmail.com
}

\begin{abstract}
Adropin plays a role in the maintenance of energy homeostasis, insulin resistance prevention, and impaired glucose tolerance. However, the molecular mechanisms by which adropin affects hepatic glucose and lipid metabolism in vitro are not entirely understood. This study intended to examine the roles and underlying mechanisms of adropin in glucose and lipid metabolism in Nile tilapia. In primary cultured tilapia hepatocytes, adropin significantly attenuated oleic acid (OA)-induced glucose output and reduced the activities and mRNA expression of cytosolic phosphoenolpyruvate carboxykinase (PEPCK) and glucose-6-phosphatase (G6Pase), which are involved in gluconeogenesis. In contrast, adropin facilitated glucose uptake activity via glucose transporter 1 (Glut1) upregulation in OA-treated hepatocytes. One-week of adropin treatment reduced the hepatic total lipid accumulation in OA-fed tilapia without changes in body weight. Subsequent studies revealed that adropin suppressed OA-induced intracellular triglyceride accumulation and decreased the expression of genes and proteins involved in lipid metabolisms such as sterol regulatory element-binding protein-1C (SREBP-1C), acetyl-CoA carboxylase $\alpha$ (ACC $\alpha$ ) and CD36, but upregulated peroxisome proliferator-activated receptor $\alpha$ (PPAR $\alpha$ ) levels. In parallel studies, however, adropin had no detectable effects on fatty acid-binding protein 4 (Fabp4) and carnitine palmitoyltransferase $1 \alpha(C p t 1 \alpha)$ mRNA expression. Furthermore, adropin treatment dose-dependently increased the phosphorylation level of AMP-activated protein kinase (AMPK). Suppression of AMPK by compound C or AMPK 1 siRNA blocked adropininduced decreases in the mature form of SREBP-1c expression, glucose output, and intracellular triglyceride content in OA-treated hepatocytes. These findings suggest that teleost adropin could suppress hepatic gluconeogenesis and triglyceride accumulation via a mechanism dependent on AMPK signalling.
\end{abstract}

\author{
Key Words: \\ - adropin \\ - glucose utilization \\ triglyceride accumulation \\ - hepatocytes \\ - tilapia
}

Journal of Endocrinology (2020) 246, 109-122

\section{Introduction}

Adropin, a product of the energy homeostasis-associated (Enho) gene, plays an important role in metabolic regulation and insulin sensitivity (Jasaszwili et al. 2020). Adropin is primarily synthesized in the liver and brain tissues of mice (Kumar etal. 2008) and fish (Lian etal.2016). The liver is an essential tissue for maintaining glucose and lipid homeostasis, and its metabolic processes are tightly regulated by neuronal and hormonal systems (Rui 2014). 
Although the expression of hepatic adropin also appears to depend on the nutritional state, the effect of fasting on adropin expression is still controversial. In mice, fasting reduces the hepatic expression of adropin (Kumar et al. 2008), whereas plasma adropin levels do not change in response to fasting in humans (Butler et al. 2012). In tilapia, fasting increases and refeeding decreases hepatic adropin gene expression (Lian et al. 2016). The causes of these discrepancies could be explained two-fold. One possible explanation for this difference could be related to speciesspecific variations. Alternatively, additional mechanisms could differentially affect adropin mRNA levels during nutritional changes, such as specific effects on mRNA stability or the involvement of additional transcription factors. The specific receptor for adropin has not yet been identified, but the existence of multiple putative adropin receptors has been suggested. Adropin-mediated activation of the orphan $G$ protein-coupled receptor 19 (GPR19) exerts its biological functions in rat brain tissues (Stein et al. 2016), breast cancer cells (Rao \& Herr 2017) and cardiac cells (Thapa et al. 2018), whereas the central effect of adropin is mediated through the activation of the transient receptor potential cation channel subfamily V 4 (TRPV4) to reduce water consumption in male rats (Yang et al. 2017).

Emerging evidence indicates that adropin plays an important role in the regulation of glucose and lipid homeostasis. In HepG2 cells, adropin expression is suppressed following activation of liver $\mathrm{X}$ receptors, suggesting sensitivity to carbohydrate and lipid metabolism (Kumar et al. 2008). In humans and male rats, associations between plasma adropin concentrations and low-density lipoprotein cholesterol suggest a link with hepatic lipid metabolism (Ghoshal et al. 2018). Adropinknockout mice were associated with increased adiposity, hepatosteatosis, and insulin resistance (Kumar et al. 2008), while transgenic overexpression or systemic adropin treatments markedly attenuates insulin resistance and glucose intolerance in diet-induced obese mice (Kumar et al. 2008, Gao et al. 2015). Furthermore, transgenic overexpression of adropin markedly reduced plasma triacylglycerol level by downregulating the expression of hepatic stearoyl-CoA desaturase- 1 and fatty acid synthase in mice (Kumar et al. 2008). In high-fat diet mice, in vivo administration of adropin suppressed hepatic glucose production and improved hepatic insulin sensitivity by decreasing the protein levels of glucose-6-phosphatase (G6Pase), CD36 and PDH kinase 4 (PDK4) expression (Thapa et al. 2019). In line with these observations, adropin has been found to regulate pyruvate dehydrogenase via mitogen-activated protein kinase (MAPK)-PDK4 signalling pathway in cardiac cells (Thapa et al. 2018). More recent in vivo work has demonstrated that adropin treatment suppresses hepatic gluconeogenesis via the CAMP/PKA/CREB and SREBP-1c signalling pathways in diet-induced obese mice (Gao et al. 2019). Also, adropin could directly decrease glucose production via PKAmediated phosphorylation in primary mouse hepatocytes (Gao et al. 2019). AMP-activated protein kinase (AMPK), a heterotrimeric enzyme complex, is the key regulator of energy metabolism in cells, which contributes to the regulation of most metabolic pathways, including glucose metabolism and lipid metabolism (Kahn et al. 2005). Recent studies have suggested that adropin triggered anti-dipsogenic effects via calmodulin-dependent protein kinase kinase-AMPK signalling in rats (Yang et al. 2017). However, whether activation of the AMPK pathway was linked to adropin-mediated glucose and lipid metabolism in primary cultured hepatocytes remains unknown.

Against this background, although it is well known that the control of glucose and lipid metabolism is closely linked with adropin, the mechanism by which adropin affects hepatic carbohydrate lipid metabolism in vitro are still poorly defined. This study intended to examine the hypothesis that adropin promotes glucose and lipid homeostasis in oleic acid (OA)-induced tilapia hepatocytes by activation of the AMPK signalling pathway. Literature data confirmed that $\mathrm{OA}$ is used to induce insulin resistance model in cultured primary hepatocytes of rat (Ochs and Harris 1986), mice (Malhi et al. 2006, Liu et al. 2007), human (Sharma et al. 2011), goose (Liu et al. 2018) and fish (Du et al. 2018). Nile tilapia (Oreochromis niloticus) is an important aquaculture species cultured worldwide. Since tilapia has well-developed digestive and metabolic organs compared with zebrafish, tilapia could be used as a better fish model for nutrition and metabolism studies (He et al. 2015). In our present study, we tested our hypothesis by (1) examining the roles of adropin on hepatic glucose utilization and lipid metabolism and (2) investigating the potential role of the AMPK signalling pathway in mediating adropin effects on hepatic glucose utilization and triglyceride content in OA-treated hepatocytes.

\section{Materials and methods}

\section{Animals}

Male tilapia was reared as previously described (Lian et al. 2016). Briefly, fish were maintained in three $300 \mathrm{~L}$ tanks (eighty fish per tank) filled with aerated freshwater at 
$28^{\circ} \mathrm{C}$ under $10 \mathrm{~h}$ dark/14 $\mathrm{h}$ light photoperiod for at least 7 days before tissue sampling and hepatocytes preparation. After anaesthesia with 0.05\% MS222 (Sigma), the fish were killed by spinosectomy according to the procedures approved by the Animal Ethics Committee of Sichuan University.

\section{Test substances}

The 32-amino acid peptide, originally derived from 38-69 fragment of tilapia adropin, was synthesized by GL Biochem (Shanghai, China) using the standard procedures for solid-phase peptide synthesis. As revealed by HPLC analysis, the purity of adropin was $\geq 98 \%$, and the homogeneity of the peptide was further confirmed by mass spectrometry. A synthetic peptide was dissolved in fish physiological saline (FPS) (Wolf 1963) and stored at $-80^{\circ} \mathrm{C}$ as $0.1 \mathrm{mM}$ stocks. OA was purchased from SigmaAldrich. To prepare the $5 \mathrm{mM} O \mathrm{OA}$, OA was mixed with free fatty acid-free BSA (Sigma) at a molar ratio of 3:1 (Oliveira et al. 2015). The stock solutions were then diluted into the pre-warmed culture medium to achieve a final solution of $250 \mu \mathrm{M}$. Pharmacological agents, both STF-31 and compound $\mathrm{C}$ were obtained from Calbiochem, and were prepared as $10 \mathrm{mM}$ frozen stocks in dimethyl sulfoxide (DMSO). In these studies, the final dilutions of DMSO were always $<0.1 \%(\mathrm{v} / \mathrm{v})$ and had no effects on target gene expression in primary cultures of tilapia hepatocytes (Supplementary Fig. 1, see section on supplementary materials given at the end of this article).

\section{Isolation and culture of primary hepatocytes}

Tilapia hepatocytes were pooled from four individual fish in each batch of experiments and were prepared by collagenase digestion method as described previously (Chow et al. 2004, Yanhong et al. 2008). Briefly, tilapia livers were perfused in situ by a pre-warmed $\left(28^{\circ} \mathrm{C}\right)$ $\mathrm{Ca}^{2+} / \mathrm{Mg}^{2+}$-free HBSS medium to wash out the blood, and then the liver fragments were digested in $\mathrm{Ca}^{2+} / \mathrm{Mg}^{2+}$ free HBSS medium with $0.5 \mathrm{mg} / \mathrm{mL}$ type IV collagenase (Sigma) and $0.01 \mathrm{mg} / \mathrm{mL}$ DNase II (Sigma) for $30 \mathrm{~min}$ with constant shaking at $28^{\circ} \mathrm{C}$. Hepatocytes were dispersed by gentle pipetting and filtered through a sterile $40 \mu \mathrm{m}$ mesh metal screen (Sigma) followed by a nylon mesh with a pore size of $-20 \mu \mathrm{m}$ to remove the undigested fragments/debris. After that, hepatocytes were harvested by centrifugation at $50 \boldsymbol{g}$ for $5 \mathrm{~min}$ and resuspended in M199 medium (Invitrogen) containing $0.5 \%$ BSA (Sigma). Hepatocytes were seeded at a density of $-0.7 \times 10^{6}$ cells/well in PEI
( $5 \mu \mathrm{g} / \mathrm{mL})$ precoated 24 -well plate and incubated overnight at $28^{\circ} \mathrm{C}$ in a humidified atmosphere of $95 \%$ air and $5 \%$ $\mathrm{CO}_{2}$. On the following day, hepatocytes were incubated with control medium or the high-fat medium containing $250 \mu \mathrm{M}$ OA, followed by vehicle (FPS) or $100 \mathrm{nM}$ adropin treatment for $24 \mathrm{~h}$ in the absence or presence of OA. The co-incubation time and concentration with the tested agents were designed based on preliminary experiments.

\section{Cell viability assay}

The viability of hepatocytes was measured using MTT assay as previously described (Fujii et al. 1995). Briefly, liver cells were seeded in 48-well plates at a density of $-0.4 \times 10^{6}$ cells/well. After incubation in medium with $100 \mathrm{nM}$ adropin or vehicle for $24 \mathrm{~h}$ in the absence or presence of OA $(250 \mu \mathrm{M})$, cell viability was determined by the reduction of MTT to formazan. The absorbance of vehicle control cells was assumed as $100 \%$ cell viability.

\section{Hepatic glucose output}

Hepatocytes were incubated with $100 \mathrm{nM}$ adropin or vehicle for $24 \mathrm{~h}$ in the absence or presence of $\mathrm{OA}$ as described above. After that, hepatocytes were washed twice with FPS to remove glucose and then incubated for $3 \mathrm{~h}$ in glucose production assay medium (glucoseand phenol red-free M199 containing gluconeogenic substrates). At the end of this incubation, media solution was used for measuring the glucose concentration using a colourimetric glucose assay kit (BioVision, Milpitas, CA, USA). Glucose production was normalized to total protein concentration as measured by the bicinchoninic acid (BCA) protein assay kit (Pierce, Thermo Fisher Scientific Inc.) with BSA as a standard to correct for potential variation in cell number.

\section{PEPCK and G6Pase activity analysis}

The activities of cytosolic phosphoenolpyruvate carboxykinase (PEPCK) (EC4.1.1.32) was determined based on the method of Bentle and Lard (Bentle \& Lardy 1976). One unit of cytosolic PEPCK activity was expressed as nanomoles NADH oxidized/min/g protein. The G6Pase (EC3. 1. 3. 9) activity was estimated using the method described by (Alegre et al. 1988). One unit of G6Pase activity was defined as the amount of enzyme that catalyzed the hydrolysis of $1 \mu \mathrm{M}$ of glucose-6-phosphate/ $\mathrm{min} / \mathrm{g}$ protein. The protein concentration of hepatic homogenates was determined by using the BCA protein 
assay kit (Pierce) with BSA as a standard. Enzyme-specific activity was expressed as unit/g soluble protein.

\section{Hepatic glucose uptake assays}

The glucose uptake ability was analyzed using a glucose uptake colourimetric assay kit according to the manufacturer's instructions (BioVision). After treatment, hepatocytes were washed with glucose uptake medium (glucose-free M199) two times and resuspended with $90 \mu \mathrm{L}$ of glucose uptake medium. The cells were incubated for $40 \mathrm{~min}$ followed by the addition of $10 \mu \mathrm{L}$ of $10 \mathrm{mM}$ 2-deoxyglucose and cultured for $1 \mathrm{~h}$ at $37^{\circ} \mathrm{C}$, and then the cells were lysed with $100 \mu \mathrm{L}$ of assay buffer (supplied in glucose uptake colourimetric assay kit). The absorbance was measured at a $412 \mathrm{~nm}$ wavelength on a microplate reader (BioTek Instruments, Inc.).

\section{Animal experiments}

After 2 weeks acclimating period, the fish were randomly assigned to the four groups ( $n=7-9 /$ group) as follows: administered with vehicle (FPS), administered with adropin (450 nmol/kg/day), OA fed administered with a vehicle, and OA fed administered with adropin (450 nmol/kg/day). The OA-fed group was treated with OA (4 mg/kg of body weight) daily by oral gavage for 7 days, and the adropin-treated group was given once daily by an intraperitoneal injection of $450 \mathrm{nmol} / \mathrm{kg} / \mathrm{day}$ adropin comparable with the concentrations previously reported (Gao et al. 2019), whereas the vehicle group received FPS $(0.1 \mathrm{~mL})$. After the 1 -week trial, the fish were fasted for $18 \mathrm{~h}$ and then killed for the collection of tissue samples. The liver tissues were frozen at $-80^{\circ} \mathrm{C}$ until subsequent analysis.

\section{Measurements of total hepatic lipid and intracellular triglyceride content}

Total liver lipids were extracted in 20 volume of chloroform: methanol $(2: 1, \mathrm{v} / \mathrm{v})$ containing $0.01 \%$ of butylated hydroxytoluene as anti-oxidant according to Folch's method (Folch et al. 1957). The extracts were evaporated in a tared rotary evaporator flask and then frozen at $-80^{\circ} \mathrm{C}$ until subsequent analysis. Cellular triglyceride content was measured using a triglyceride assay kit (JianCheng Bioengineering Institute, Nanjing, China) according to the manufacturer's instructions and normalized to total protein concentration.

\section{Oil Red O staining of liver tissue}

For Oil Red O staining, frozen liver tissues were cut into $7 \mu \mathrm{m}$ with Probe-On-Plus Slides (Thermo Fisher Scientific) and fixed to microscope slides. Sections were reacted with Oil Red $\mathrm{O}$ solution buffer for $7 \mathrm{~min}$ at $60^{\circ} \mathrm{C}$ and then incubated with $85 \%$ propylene glycol for $3 \mathrm{~min}$. After rinsing with distilled water, sections were stained with haematoxylin for counterstaining.

\section{Quantitative real-time PCR assays}

Total RNA was extracted from tilapia hepatocytes by TRIzol reagent (Life Technologies) followed by chloroform/isopropanol extraction. RNA was quantified using NanoDrop 2000 spectrophotometer (Thermo Scientific), and $1 \mu \mathrm{g}$ of total RNA was reverse transcribed using iScript ${ }^{\mathrm{TM}}$ RT Supermix (Bio-Rad). qPCR assays were performed on a Mastercycler ${ }^{\circledR}$ ep realplex system (Eppendorf) with SYBR Green Mix (Bio-Rad) and analyzed using the software Realplex 2.2 (Eppendorf). The cycling conditions were the following: 2 min incubation at $95^{\circ} \mathrm{C}$, 45 amplification cycles $\left(95^{\circ} \mathrm{C}\right.$ for $30 \mathrm{~s}, 60^{\circ} \mathrm{C}$ for $30 \mathrm{~s}$, and $45 \mathrm{~s}$ at $75^{\circ} \mathrm{C}$, with fluorescence detection at the end of each cycle), followed by melting curve of the amplified products obtained by ramped increase of the temperature from 55 to $95^{\circ} \mathrm{C}$ to confirm the presence of single amplification product per reaction. Primer sequences are provided in Table 1, and the specificity of each primer pair was verified by the previous study in tilapia (He et al. 2015, Lian et al. 2016). $\beta$-Actin was used as an internal control for normalizing genes of interest, and transcript levels were analyzed using the $2^{-\Delta \Delta \mathrm{CT}}$ method.

\section{Western blot analysis}

Western blot was performed as described previously (Jiang \& Wong 2013). Proteins were separated on SDS-PAGE gels, transferred to PVDF (polyvinylidene difluoride, Millipore), and incubated with antibodies against SREBP-1c (1:1000, Santa Cruz Biotechnology), ACC $\alpha$ (1:1000, Santa Cruz Biotechnology), CD36 (1:1000, Santa Cruz Biotechnology), PPAR $\alpha$ (1:1000, Santa Cruz Biotechnology), phospho-AMPKo (1:1000, Cell Signaling Technology), AMPK $\alpha$ (1:1000, Cell Signaling Technology), Lamin b (1:1000, Cell Signaling Technology) and $\beta$-actin $(1: 5,000 ;$ Cell Signaling Technology) for overnight at $4^{\circ} \mathrm{C}$. These antibodies have been used previously in zebrafish (Liu et al. 2017), tilapia (Ning et al. 2017) and bream (Shi et al. 2018), 
Table 1 Real-time primer sequences for genes of interest.

\begin{tabular}{|c|c|}
\hline Primer name & Sequence $\left(5^{\prime}\right.$ to $\left.3^{\prime}\right)$ \\
\hline Pepck1 forward & TGCCAGCCAGACTCCATTCACA \\
\hline Pcpck1 reverse & АCTCTCCACACGAGCCACATCC \\
\hline G6pca forward & ATCGGAGACTGGCTCAACTTGGT \\
\hline G6pca reverse & TGGCATGACCTGAAGGACTTCCT \\
\hline Glut1 forward & GTTGGAACTGCGGTGATTGGCT \\
\hline Glut1 reverse & ATAGCAACAGCGATGGACCACAC \\
\hline Glut2 forward & GGCACTCTAGCTCTGGCTGTGT \\
\hline Glut2 reverse & GGGTGGTGACCTGGGTCTTCTT \\
\hline Srebp1c forward & ATTCAGACTCAGCTCCAAGGG \\
\hline Srebp1c reverse & TCAGGCTTCAAAGTGGTCAG \\
\hline$A c c \alpha$ forward & GGAGTTCGGACAGCACCTATGAA \\
\hline$A c c \alpha$ reverse & AGCAGGAGAAGCAACAGTGAAGT \\
\hline Cd36 forward & GCAGCAGTACCAGCGATTCCT \\
\hline Cd36 reverse & TCTCCAGTACGCAGCCAGGA \\
\hline Fabp4 forward & AAGCTGGGAGAGGAGTTTGATGAA \\
\hline Fabp4 reverse & TCTCTTTGCCGTCCCACTTCT \\
\hline Ppara forward & CTGATAAAGCTTCGGGCTTCCA \\
\hline Ppara reverse & CGCTCACACTTATCATACTCCAGCT \\
\hline Cpt1a forward & TTTCCAGGCCTCCTTACCCA \\
\hline Cpt1a reverse & TTGTACTGCTCATTGTCCAGCAGA \\
\hline$\beta$-actin forward & GTGATGGTGGGTATGGGT \\
\hline$\beta$-actin reverse & GGCAACTCTCAGCTCGTT \\
\hline
\end{tabular}

confirming that epitopes detected by these antisera are highly homologous to that of the fish counterparts. After washing blots to remove excessive primary antibody binding, the blots were incubated for $1 \mathrm{~h}$ with horseradish peroxidase (HRP)-conjugated secondary antibody. Blots were developed by SuperSignal WestPico chemiluminescent substrate (Pierce) using the FluorChem FC2 detection system (Biozym Scientific). ImageJ was used to analyze the densitometric values.

\section{RNA interference}

The siRNA constructs against AMPK 1 mRNA (the predominant isoform of AMPK in tilapia liver (Xu et al. 2002)), as well as scrambled control siRNA, were designed and synthesized by Gene Pharma (Shanghai, China). RNAi was introduced into primary hepatocytes by reverse transfection with siRNA-Mate (GenePharma) according to the manufacturer's protocol. Briefly, the siRNA transfection mixture was applied to PEI-coated six-well plates right before the plating of primary hepatocytes in culture media without antibiotics. The experiments were performed $24 \mathrm{~h}$ after transfection. Gene silencing was verified by detecting protein with immunoblot analysis after transient transfection of hepatocytes with siRNA. The siRNA sequences are as follows: AMPK $\alpha 1$ (sense 5'-GGAGAGUUCCUUAGAACAAdTdT-3' and anti-sense 5'-UUGUUCUAAGGAACUCUCCdTdT-3'); and scrambled
siRNA (sense 5'-GGAUUGUCCGAUAAGACAAdTdT-3' and anti-sense 5'-UUGUCUUAUCGGACAAUCCdTdT-3').

\section{Statistics analysis}

Three biological replicates were analyzed, and four technical repeats were performed per sample. All results are expressed as the mean \pm s.E.M. $(n=3)$. Data were analyzed using ANOVA followed by post hoc Bonferroni's test that was used for the multiple comparisons. A value of $P<0.05$ was considered statistically significant. All analyses were performed with GraphPad Prism Software, Inc.

\section{Results}

\section{Adropin reduced glucose output and inhibited gluconeogenesis in tilapia hepatocytes}

To determine whether adropin regulates hepatic gluconeogenesis, glucose output analysis was performed on OA-treated tilapia primary hepatocytes. The level of glucose output was significantly increased in hepatocytes with $250 \mu \mathrm{M}$ OA treatment, which was more than 1.5 -fold higher than vehicle control, whereas these stimulatory effects were not seen when the cells were co-incubated in the presence of $100 \mathrm{nM}$ adropin. In contrast, no significant changes were found in the level of glucose production in hepatocytes treated with vehicle control compared to adropin alone $(3.05 \pm 0.26 \mu \mathrm{g} / \mathrm{mg}$ protein vs $2.80 \pm 0.33 \mu \mathrm{g} / \mathrm{mg}$ protein; $P>0.05$ ) (Fig. $1 \mathrm{~A}$ ). To rule out the possibility that the inhibitory effect is due to a decreased cell number, we tested the effects of adropin and OA on hepatocyte viability. The results showed that adropin, $\mathrm{OA}$, or the combined treatment exhibited no toxic effects at the indicated dosages (Fig. 1B). PEPCK and G6Pase are rate-limiting enzymes regulating hepatic gluconeogenesis (Yabaluri \& Bashyam 2010). To determine whether adropin-reduced glucose output was attributed to decreases in the rate of the hepatic gluconeogenesis, effects of adropin on PEPCK and G6Pase activities were examined in OA-treated tilapia hepatocytes. As shown in Fig. $1 \mathrm{C}$ and D, OA treatment enhanced PEPCK $(-80 \%$ increase, $P<0.05)$ and G6Pase $(-50 \%$ increase, $P<0.05)$ activities compared to vehicle control. In contrast, adropin was effective in negating the stimulation of PEPCK and G6Pase activities in OA-treated hepatocytes. In parallel studies, adropin could negate OA-increased cytosolic pepck1 and g6pca gene expression (Fig. 1E and F), suggesting that the inhibition of adropin on PEPCK 

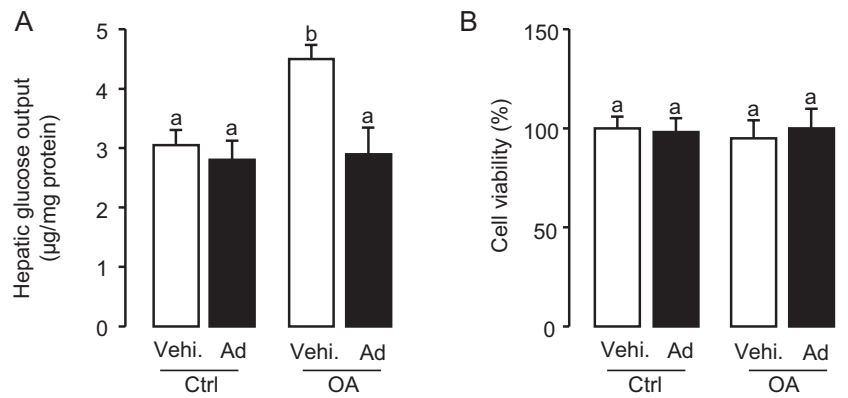

C
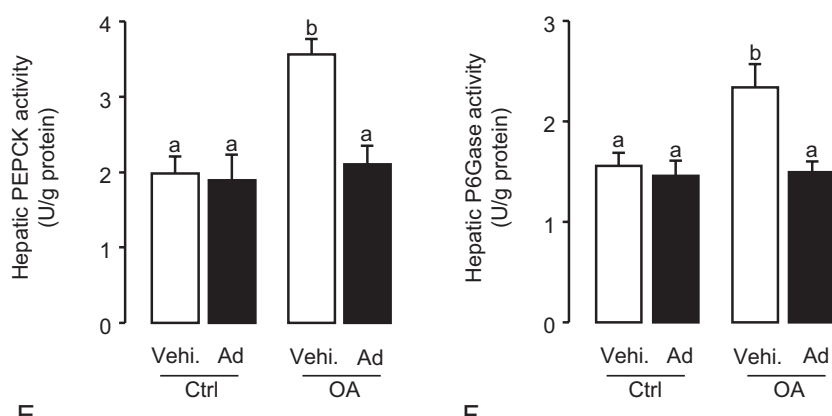

$\mathrm{F}$
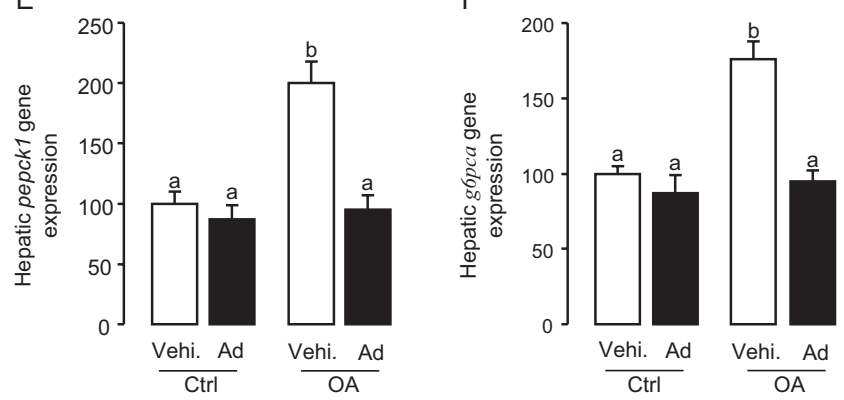

Figure 1

Adropin treatment suppresses glucose production and the key enzymes of gluconeogenesis in OA-treated tilapia hepatocytes. (A) The effect of adropin inhibition on OA-induced glucose output. (B) The effect of adropin treatment on hepatocytes viability. Cell viability was determined by MTT assay. (C) and (D) Inhibitory effects of adropin on PEPCK and G6Pase activities. (E) and (F) Inhibitory effects of adropin on pepck1 and g6pca mRNA expression. Genes were measured by qPCR and normalized to $\beta$-actin levels. Three biological replicates were analyzed, and four technical repeats were performed per sample. All results are expressed as the mean \pm S.E.M. $(n=3)$. Different superscript letters in each column show significant differences $(P<0.05$, two-way ANOVA).

and G6Pase activities is due to decreases in mRNA levels of these enzymes.

\section{Adropin increased glucose uptake via the activation of GLUT1 gene expression in OA-treated hepatocytes}

To further investigate the effects of adropin on glucose utilization, glucose uptake assay was performed in OA-treated hepatocytes. As shown in Fig. 2A, the level of glucose uptake significantly decreased in response to OA compared to that in the vehicle control, whereas co-treatment with adropin at $100 \mathrm{nM}$ significantly increased glucose uptake compared to cells treated with OA only. To investigate whether the glucose transporters (GLUTs) are involved in elevated glucose uptake in hepatocytes, we analyzed the mRNA expression of glut1 and glut2. Glut4 was excluded because it was known that glut4 mRNA was found to be scarcely expressed in the liver tissue of tilapia (Chen et al. 2017). The gene expression of hepatic glut1 and glut2 decreased in OA-treated cells, whereas the transcription of glut1 but not glut2 mRNA was upregulated by co-treatment with adropin (Fig. 2B and C). Since the expression level of glut1 appeared to correspond to the glucose uptake ability, we predicted that GLUT1 might play a central role in the glucose uptake in hepatocytes. To evaluate the involvement of GLUT1 in adropin-mediated glucose uptake, the stimulatory effects of adropin $(100 \mathrm{nM})$ on glucose uptake were examined with co-treatment of the STF-31 $(5 \mu \mathrm{M})$, a selective GLUT1 inhibitor. Consistently, glucose uptake was inhibited by

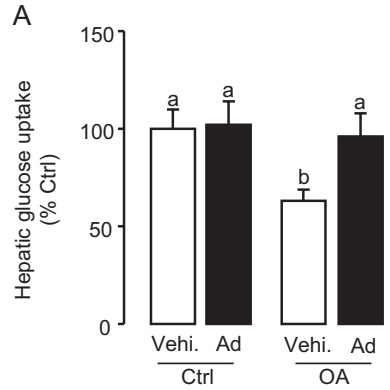

C

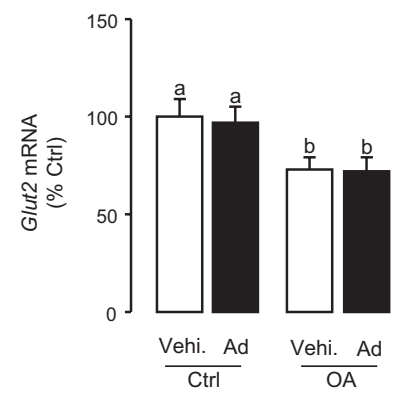

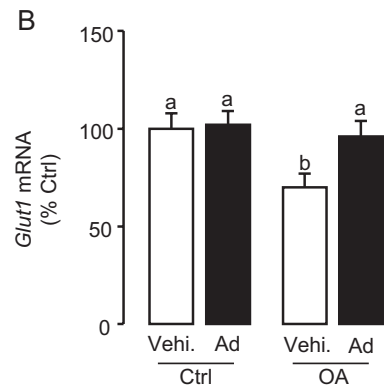

D

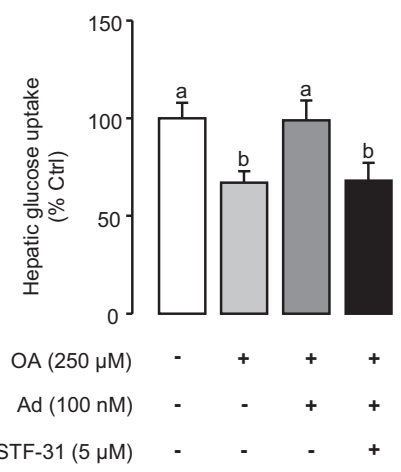

Figure 2

Adropin induces glucose uptake in hepatocytes. (A) The effects of adropin on the glucose uptake in OA-treated hepatocytes. (B) and (C) The effects of adropin on the mRNA expression of g/ut 1 and g/ut 2 in OA-treated hepatocytes. Genes were measured by qPCR and normalized to $\beta$-actin levels. (D) The effect of GLUT1 inhibition on adropin-induced glucose uptake. Three biological replicates were analyzed, and four technical repeats were performed per sample. All results are expressed as the mean \pm S.E.M. $(n=3)$. Different superscript letters in each column show significant differences $(P<0.05$, two-way ANOVA). 
OA exposure, whereas adropin-stimulated glucose uptake was abrogated by STF-31 in the presence of OA (Fig. 2D).

\section{Adropin ameliorated the OA-mediated hepatic lipid accumulation}

Since hepatic glucose utilization and lipid content are associated, the effect of adropin on hepatic lipid metabolism was then assessed by in vivo and in vitro experiments. The in vivo effects of adropin were assessed in the OA-fed tilapia. As shown in Fig. 3A, there were no significant differences in weight gain between OA-fed tilapia and OA-fed adropin-administered tilapia. However, OA feeding increased the hepatic total lipid content markedly when compared with vehicle control, and adropin treatment significantly reduced lipid content under basal or OA-fed conditions (Fig. 3B). Histological examination of Oil Red $\mathrm{O}$ staining of the cryosectioned liver tissue showed the accumulation of lipid droplets in OA-fed tilapia liver, whereas only a small number of lipid droplets were observed in the livers of normal diet-fed tilapia. Lipid droplets were greatly reduced in the livers of OA-fed adropin-administered tilapia (Fig. 3C). To explore the effect of adropin on hepatic triglyceride accumulation in vitro, hepatic triglyceride contents were measured in OA-induced hepatocytes. Analysis of intracellular lipids revealed a dramatic increase in triglyceride content in OA-treated hepatocytes. As expected, a decrease in triglyceride content was observed in cells treated with adropin in comparison with the only OA-treated cells $(P<0.001, \mathrm{OA}$ vs $\mathrm{OA}+\mathrm{Ad})$. Of note, adropin treatment alone also could reduce triglyceride content in hepatocytes $(P<0.05$, Vehi. vs Ad) (Fig. 3D).

\section{Adropin altered the expression of lipid metabolic genes in OA-treated hepatocytes}

To address the molecular mechanism underlying the suppressive effect of adropin on lipid accumulation in hepatocytes, we examined the effects of adropin on the expression of genes associated with lipid metabolism. As shown in Fig. 4A and B, we found that adropin treatment at $100 \mathrm{nM}$ for $24 \mathrm{~h}$ slightly, but significantly, decreased the gene expression levels of sterol regulatory elementbinding protein-1c (srebp-1c) and acetyl-CoA-carboxylase alpha $(a c c \alpha)$ in the absence of OA $(P<0.05$, Vehi. vs Ad). Furthermore, OA treatment led to a -2.1-fold and -1.6fold increases in srebp-1c and acco mRNA levels when compared with that in the vehicle control, respectively, and these increases could be prevented by co-treatment with adropin. Furthermore, adropin suppressed the OA-induced increase in mRNA levels of $c d 36$ (Fig. 4C),
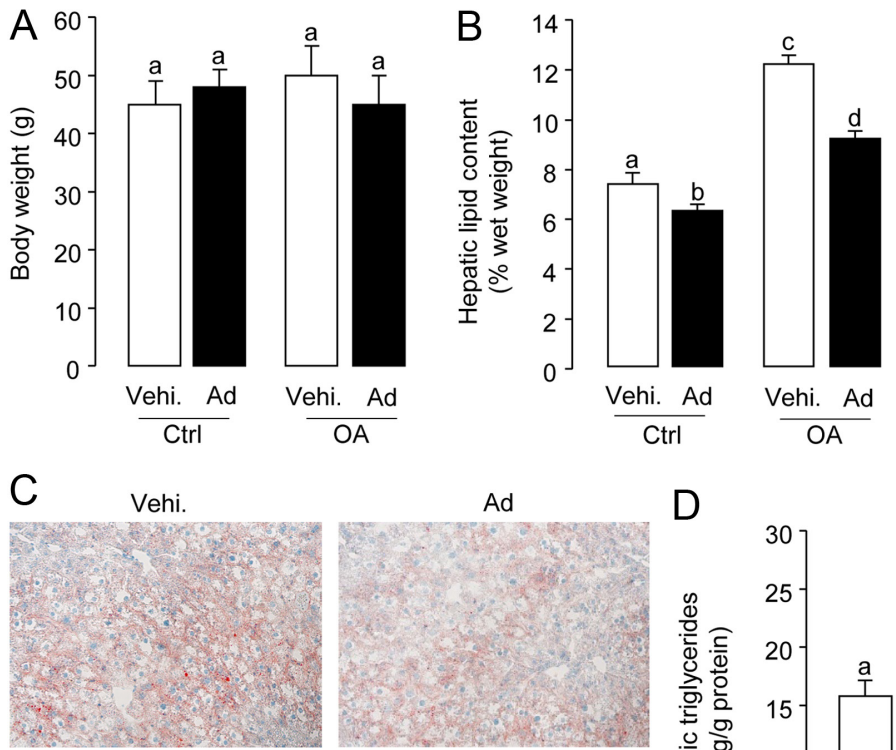

Vehi.+ OA
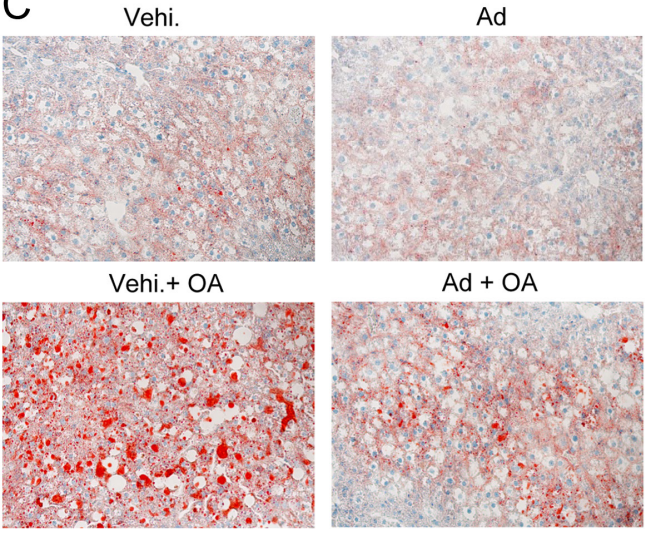

D

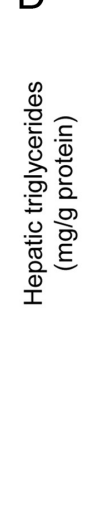

(C) 2020 Society for Endocrinology Published by Bioscientifica Ltd. Printed in Great Britain

\section{Figure 3}

Effects of adropin on hepatic lipid accumulation both in vivo and in vitro. (A) The effect of adropin on body weight of OA-fed tilapia. (B) Adropin suppressed hepatic total lipid content in OA-fed tilapia. (C) Representative histological section analysis of inhibitory effects of adropin on lipid droplet formation in liver stained by Oil Red $\mathrm{O}$ staining. The tissue slides were examined under a light microscope at a magnification of $\times 200$. (D) Inhibitory effects of adropin on triglyceride content in hepatocytes with OA treatment. Three biological replicates were analyzed, and four technical repeats were performed per sample. All results are expressed as the mean \pm S.E.M. $(n=3)$ Different superscript letters in each column show significant differences ( $P<0.05$, two-way ANOVA). A full colour version of this figure is available at https://doi.org/10.1530/JOE-20-0077. https://joe.bioscientifica.com https://doi.org/10.1530/JOE-20-0077 
A

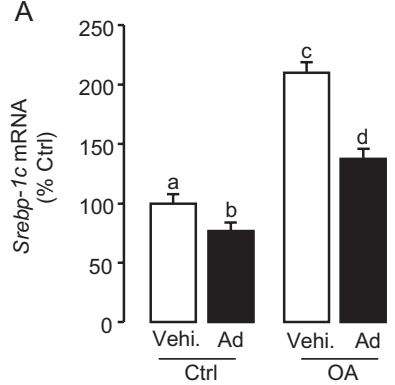

B

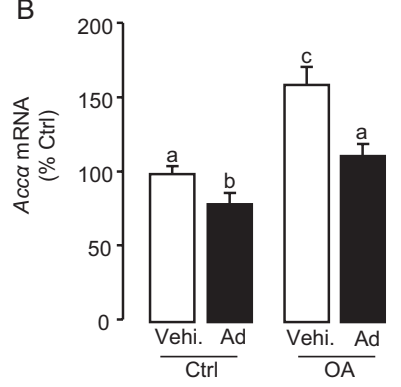

C

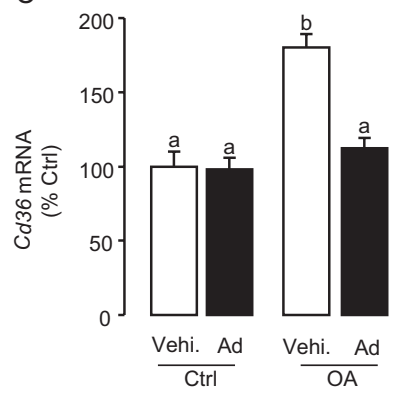

E

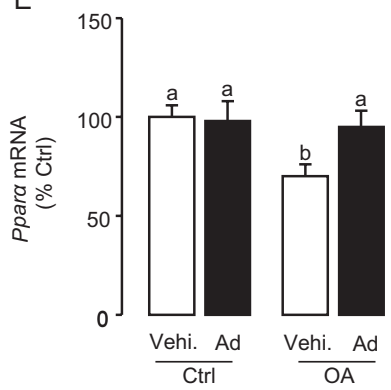

D

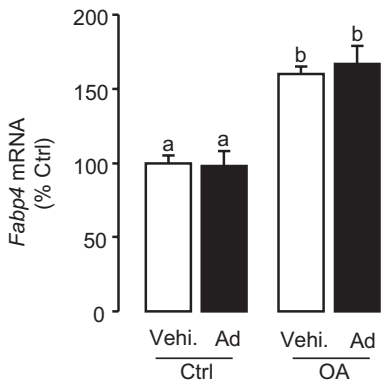

$\mathrm{F}$

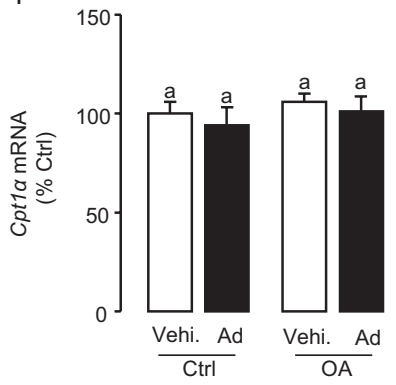

Figure 4

Adropin regulates the expression of lipid metabolism-related genes in tilapia hepatocytes. The effects of adropin on mRNA expression levels of lipogenic genes: (A) Srebp-1c and (B) $A c c \alpha$, fatty acid transporter genes: (C) Cd36 and (D) Fabp4, and fatty acid oxidation genes: (E) Ppara and (F) Cpt1 $\alpha$. Lipid metabolism-related genes were measured by qPCR and normalized to $\beta$-actin levels. Three biological replicates were analyzed, and four technical repeats were performed per sample. All results are expressed as the mean \pm S.E.M. $(n=3)$ and expressed as percentages of the vehicle control values. Different superscript letters in each column show significant differences $(P<0.05$, two-way ANOVA).

whereas adropin rescued the OA-inhibited peroxisome proliferator-activated receptor alpha (ppar $\alpha$ ) gene expression (Fig. 4E). However, a similar dose of adropin did not alter fatty acid-binding proteins 4 (Fabp4) and carnitine palmitoyltransferase $1 \alpha$ (Cpt1a) mRNA levels in OA-treated hepatocytes (Fig. 4D and F).

\section{Adropin regulated the expression of lipid metabolism- related proteins in OA-treated hepatocytes}

Consistent with the role of adropin in the regulation of lipogenic genes expression, we observed that the

mature form of SREBP-1c was dose-dependently reduced in OA-treated hepatocytes with adropin treatment. The maximal inhibition of SREBP-1c response to adropin was estimated to be approximately $41 \%$ (Fig. 5A). In parallel experiments, cells treated with adropin also exhibited a strong dose-dependent downregulation of ACC $\alpha$ protein expression in OA-treated hepatocytes. The minimal effective dose for adropin to decrease ACC $\alpha$ expression could be observed at $10 \mathrm{nM}$. At the highest dose of adropin treatment, the ACC $\alpha$ level was reduced to near control level (Fig. 5B). To further determine how adropin alters lipid metabolism, we measured the protein expression of CD36 and PPAR $\alpha$, which are essential for lipid uptake and $\beta$-oxidation, respectively. After being treated with $250 \mu \mathrm{M} \mathrm{OA}$, hepatocytes showed a marked increase in the protein level of CD36 (Fig. 5C) and a significant decrease in the protein levels of PPAR $\alpha$ (Fig. 5D). However, the intervention of adropin dose-dependently
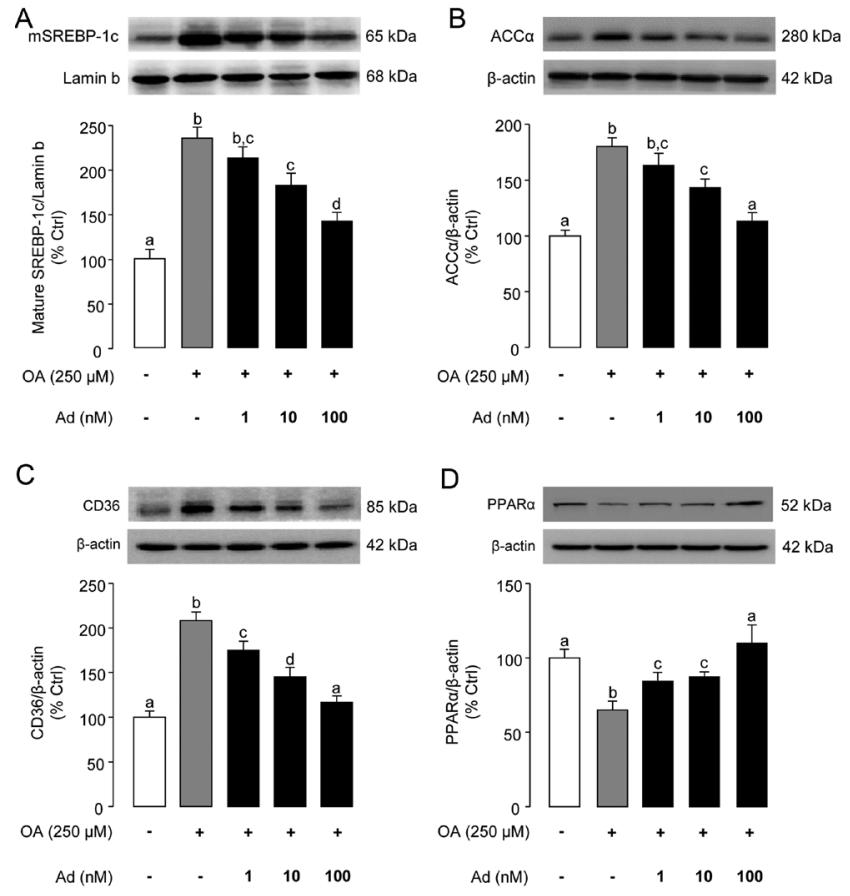

\section{Figure 5}

Adropin regulates the expression of lipid metabolism-related proteins in tilapia hepatocytes. Dose-dependence of adropin induction on (A) mature SREBP-1C, (B) ACC $\alpha$, (C) CD36, and (D) PPAR $\alpha$ protein expression in OA-treated hepatocytes. Representative bands of mature SREBP-1C, ACC $\alpha$, CD36 and PPAR $\alpha$ were detected by Western blot (gel bands). Parallel blottings of Lamin $b$ and $\beta$-actin were used as a loading control for nuclear and cytoplasmic proteins, respectively. Blots represent prototypical examples of experiments. Three biological replicates were analyzed, and four technical repeats were performed per sample. All results are expressed as the mean \pm S.E.M. $(n=3)$. Different superscript letters in each column show significant differences $(P<0.05$, one-way ANOVA). 
decreased the level of CD36 to upregulate the fatty acid translocase (Fig. 5C), but increased the level of PPAR $\alpha$ in a dose-related manner, which regulates genes involved in $\beta$-oxidation (Fig. 5D).

\section{AMPK pathway mediated adropin-reduced glucose output and triglyceride accumulation in OA-treated hepatocytes}

As a cellular energy regulator, AMPK signalling plays an important role in glucose and lipid metabolism (Ceddia 2013). To investigate whether this signalling mechanism regulates hepatic glucose and triglyceride metabolism induced by adropin in a high-fat environment, we evaluated the AMPK phosphorylation in OA-treated hepatocytes. Western blot analysis indicated that 250 $\mu \mathrm{M}$ OA suppressed the phosphorylation of AMPK $\alpha$ at Thr-172, which is essential for AMPK activation. In contrast, the addition of adropin significantly enhanced phosphorylated AMPK $\alpha$ levels in a dose-dependent manner. The maximum stimulatory effect on the activation of phosphorylated AMPK $\alpha$ was observed at the dosage range from 10 to $100 \mathrm{nM}(P<0.05$ vs OA treatment alone) (Fig. 6A). These results indicated the promoting function of adropin on AMPK activity. To further explore the possibility that AMPK is involved in adropin-induced glucose utilization and triglyceride accumulation in OA-treated hepatocytes, compound C, a specific inhibitor of AMPK, was used to block the activation of AMPK. As shown in Fig. 6B, Western blot analysis of the nuclear fractions demonstrated that blockade of AMPK activity by compound $\mathrm{C}$ completely attenuated the inhibition of SREBP-1c nuclear translocation induced by adropin in the presence of OA. Furthermore, compound C treatment significantly reversed the adropin-mediated suppression of the glucose output (Fig. 6C) and triglyceride content (Fig. 6E) in the presence of OA. In parallel experiments, however, pretreatment with compound $\mathrm{C}$ was not effective in blocking the stimulatory effects of adropin on glucose uptake in OA-treated hepatocytes (Fig. 6D). To further investigate the association between AMPK and adropin-induced glucose output and triglyceride levels in hepatocytes, AMPK $\alpha 1$ siRNA was administered to block the AMPK signalling. The downregulation of AMPK in siRNA-transfected hepatocytes was confirmed by Western blotting (Fig. 7A). Consistently, knockdown of AMPK $\alpha 1$ abolished the repression of nuclear SREBP-1C translocation (Fig. 7B), glucose output (Fig. 7C) and triglyceride accumulation (Fig. 7D) evoked by adropin in tilapia hepatocytes.

(C) 2020 Society for Endocrinology Published by Bioscientifica Ltd. Printed in Great Britain

\section{Discussion}

Several lines of evidence have supported that adropin plays a role in the physiological regulation of metabolic homeostasis. It has demonstrated that adropin-knockout mice are insulin resistant, while transgenic overexpression of adropin leads to improved glycemic control (Kumar et al. 2008). Under hyperinsulinemic-euglycemic clamp conditions, adropin-knockout mice attenuated suppression of endogenous glucose production by insulin (Ganesh Kumar et al. 2012). In complementary studies, adropin treatment of obese mice led to a suppression basal and insulin-stimulated hepatic glucose production

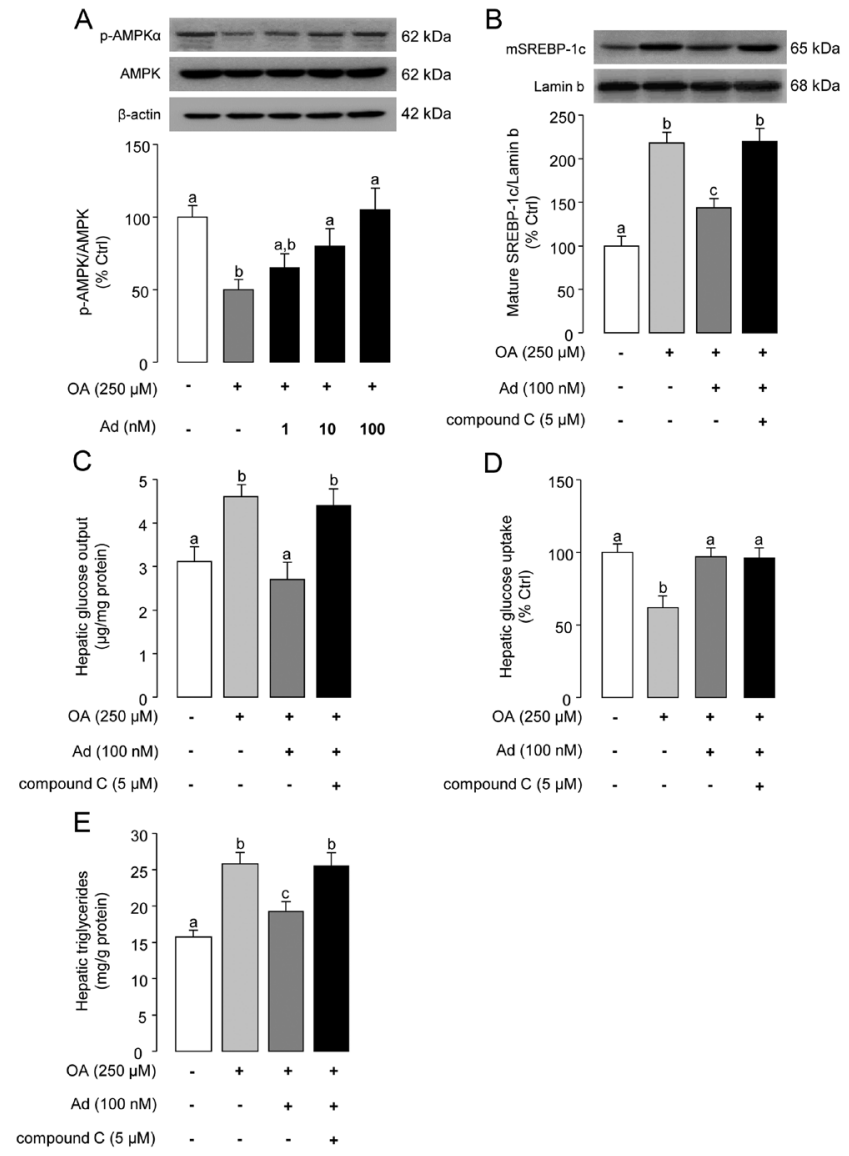

\section{Figure 6}

The effect of adropin on gluconeogenesis and triglyceride content is dependent on AMPK in OA-induced hepatocytes. (A) Effects of adropin on AMPK $\alpha$ phosphorylation in hepatocytes cells. After drug treatment, AMPKo phosphorylation was detected by Western blot analysis (gel bands). The ratio of phosphorylated/total form of the proteins of AMPK was used as a measure of activation. Effects of AMPK inhibition on adropin-induced (B) mature SREPB-1c protein expression, (C) Glucose output, (D) Glucose uptake, and (E) Triglyceride content. Three biological replicates were analyzed, and four technical repeats were performed per sample. All results are expressed as the mean \pm s.E.M. $(n=3)$. Different superscript letters in each column show significant differences $(P<0.05$, one-way ANOVA). 

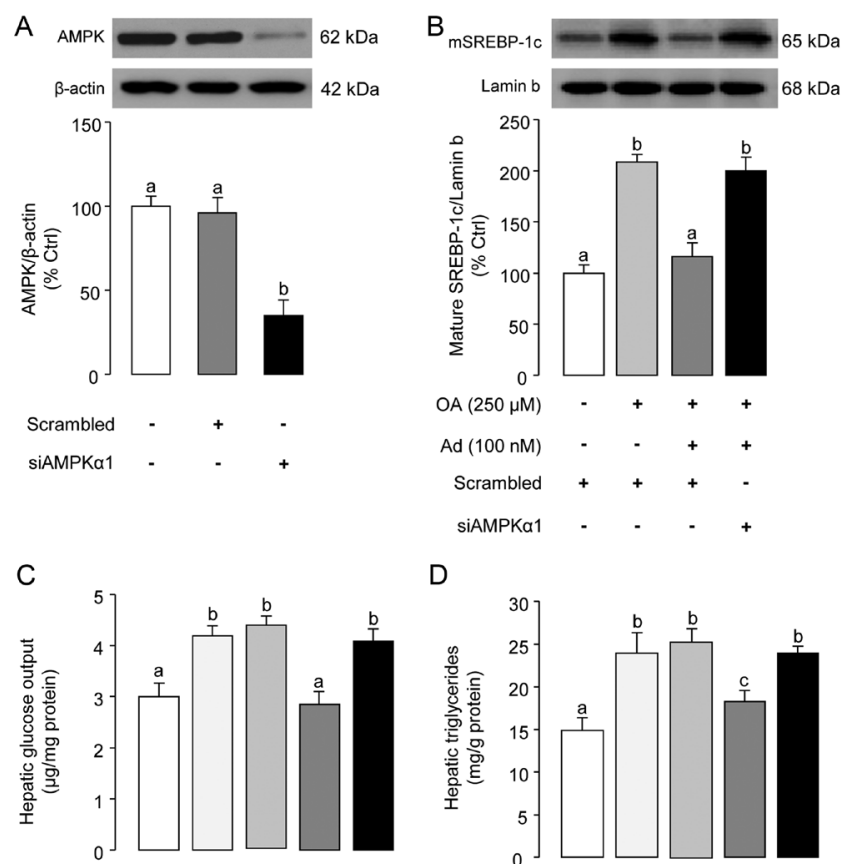

D

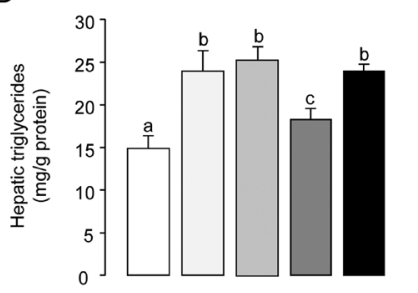

\begin{tabular}{|c|c|c|c|c|c|c|c|c|c|c|}
\hline $\mathrm{OA}(250 \mu \mathrm{M})$ & - & + & + & + & + & $\mathrm{OA}(250 \mu \mathrm{M})$ & - & + & + & \\
\hline Ad $(100 \mathrm{nM})$ & - & - & $\cdot$ & + & + & $\mathrm{Ad}(100 \mathrm{nM})$ & - & - & - & \\
\hline Scrambled & + & + & - & + & - & Scrambled & + & + & - & \\
\hline siAMPKa1 & - & - & + & - & + & siAMPKa1 & - & - & + & \\
\hline
\end{tabular}

Figure 7

Knockdown of AMPK $\alpha 1$ abolished the effects of adropin on glucose output and triglyceride accumulation in tilapia hepatocytes. Hepatocytes were transfected with control (scrambled) or AMPK-targeting siRNA (siAMPK $\alpha 1$ ) and stimulated with adropin (100 nM) $24 \mathrm{~h}$ later. (A) AMPK protein expression after siRNA transfection was determined by Western blot analysis. Effects of AMPK knock-down on adropin-induced (B) mature SREPB-1c protein expression, (C) Glucose output, and (D) Triglyceride content. Three biological replicates were analyzed, and four technical repeats were performed per sample. All results are expressed as the mean \pm S.E.M. $(n=3)$. Different superscript letters in each column show significant differences $(P<0.05$, one-way ANOVA).

(Thapa et al. 2019). The recent in vitro and in vivo studies indicated that adropin treatment downregulated the expressions of g6pase, whereas having no effect of adropin on suppression of pepck gene expression in mice (Gao et al. 2019, Thapa et al. 2019). Consistent with previous findings, the present study provides evidence that adropin inhibited hepatic glucose production. Hepatic glucose production is mainly regulated by PEPCK and G6Pase, which are important to catalyze the ratelimiting steps in gluconeogenesis, and their activities are primarily modulated through hormonal control of transcription (Yabaluri \& Bashyam 2010). In our current studies, adropin is effective in suppressing the level of the enzyme activities and transcriptions of PEPCK and G6Pase in OA-induced hepatocytes. Therefore, the decreased gluconeogenesis apparently contributes to the adropin-induced reduction in glucose production in OA-induced hepatocytes. Also, loss of adropin production reduces glucose uptake in gastrocnemius and diaphragm muscles (Ganesh Kumar et al. 2012), whereas adropin treatment significantly decreases in whole-body glucose uptake under hyperinsulinemic conditions (Thapa et al. 2019). These previous studies indicate that adropin plays an essential role in controlling glucose uptake in mouse models. However, the exact effects of adropin on hepatic glucose uptake and underlying mechanisms in vitro are not fully understood. The current results showed that adropin could enhance OA-reduced glucose uptake in hepatocytes. It is well established that the increased glucose uptake in hepatocytes has been primarily attributed to the upregulation of GLUTs (Karim et al. 2012). In search of the mechanism by which adropin enhances glucose uptake, we analyzed the gene expression of different GLUT subtypes. Adropin abrogated OA-reduced glut1 mRNA level, but did not alter glut2 gene expression in OA-treated hepatocytes. Since the changes in the gene expression level of glut 1 appeared to correspond to the glucose uptake ability, the effect of STF-31, a selective GLUT1 inhibitor, on the glucose uptake activity was tested. Our results clearly showed that adropin-stimulated glucose uptake in OA-treated hepatocytes was completely suppressed by treatment with STF-31, suggesting that GLUT1 plays a central role in adropin-mediated glucose uptake activity of tilapia hepatocytes. Therefore, adropin exerts its glucoselowering effect in OA-induced hepatocytes by suppressing gluconeogenesis and facilitating glucose uptake.

Apart from governing glucose utilization, it has been found that circulating adropin is suppressed by obesity in mice (Kumar et al. 2008) and humans (Butler et al. 2012). Transgenic overexpression of adropin markedly reduced plasma triacylglycerol levels in diet-induced obese mice (Kumar et al. 2008). Adropin-knockout mice exhibit increased adiposity, fasting triglycerides and hepatic steatosis (Ganesh Kumar et al. 2012). Moreover, intraperitoneal administration of adropin to hyperlipidemic rats for 10 days was extremely effective in decreasing the levels of serum triglycerides (Akcilar et al. 2016). In contrast, short-term treatment of adropin failed to result in significant reductions in triacylglycerol levels in diet-induced obese mice (Gao et al. 2019). In tilapia, adropin treatment has no significant effect on OA-fed tilapia body weight, which is consistent with previous results from mice studies (Kumar et al. 2008), whereas intraperitoneal administration of adropin could significantly attenuate hepatic lipid content in OA-fed tilapia. Studies in Atlantic salmon have shown increased 
total hepatic lipid storage with increasing levels of OA in the diet (Stubhaug et al. 2005). Oil Red O staining confirmed massive red-stained lipid accumulation in the OA-fed tilapia liver tissue. In contrast, the administration of adropin significantly ameliorated lipid droplet accumulation in the liver. In vitro studies further confirmed that OA treatment alone caused a significant increase in triglyceride accumulation in hepatocytes. Especially, pretreatment of adropin inhibited OA-induced triglyceride levels. Our present results demonstrated that adropin could decrease hepatic lipid accumulation in vivo and in vitro and suggested that adropin has potential hepatoprotective effects in hyperlipidemic fish.

Hepatic lipid accumulation may be primarily caused by increased de novo lipid synthesis, enhanced lipid uptake and suppressing of lipid catabolism. SREBP-1c is well known as the transcription factor that induces key hepatic lipogenic enzymes to promote lipogenesis (Horton et al. 2002). In cultured rat hepatocytes, insulin increases SREBP-1c transcriptional level, whereas glucagon decreases SREBP-1c gene expression (Foretz et al. 1999). Recent studies have provided evidence that the inhibition expression of SREBP-1c has been observed in adropintreated diet-induced obese male mice (Kumar et al. 2008, Gao et al. 2019), whereas srebp-1c mRNA was increased in adropin knockout mice (Ganesh Kumar et al. 2012). However, the regulation of this transcription factor by adropin in vitro is not fully clarified. Our results support such a mechanism, showing that adropin inhibited OA-mediated increases in srebp-1c gene expression. Moreover, such effects were confirmed by Western blotting in which the protein levels of the nuclear translocation of SREBP-1c in hepatocytes elevated by OA exposure and abrogated by adropin. Activation of SREBP-1c is known to regulate the expression of a battery of lipid metabolic enzymes that include ACC $\alpha$ (Talukdar \& Hillgartner 2006), CD36 (Mencarelli et al. 2010) and PPAR (Bougarne et al. 2018). ACC $\alpha$ is a cytosolic enzyme that is a key regulatory step in the fatty acid synthesis pathway (Chen et al. 2019). Studies in mice support that liver-specific deletion of ACC $\alpha$ reduces hepatic triglyceride accumulation (Mao et al. 2006). CD36 is known as fatty acid translocase because it binds long-chain free fatty acids and facilitates their transport into cells (Garcia et al. 2019), which elevated expression levels with high-fat diets in human (Miquilena-Colina et al. 2011) and mice (Wilson et al. 2016). Hepatocyte-specific disruption of CD36 leads to reduced fatty liver and enhances insulin sensitivity in highfat diet mice (Wilson et al. 2016). It has been shown that injected adropin suppressed the protein expression levels of CD36 in high-fat diet mice (Thapa et al. 2019). Here we demonstrated that adropin inhibited OA-mediated increases in the gene and protein expression levels of ACC $\alpha$ and CD36, suggesting that adropin stimulated lipid metabolism through combined inhibition of lipogenesis and lipid uptake. This, however, contradicts the study of Kumar et al. (2008), which documented adropin treatment failed to affect ACC $\alpha$ and CD36 mRNA expression in the diet-induced obese male mice liver. This difference could be attributed to different species, dietary fatty acids, as well as genes under consideration. The FABPs gene family comprises a group of high-affinity intracellular fatty acid-binding proteins (Zimmerman \& Veerkamp 2002). Expression levels of Fabp4 in this study were not significantly altered by adropin. Given that different FABP isoforms shared similar functions in lipid homeostasis (Zimmerman \& Veerkamp 2002), we could not exclude the possibility that other isoforms of FABP could be involved in adropin-mediated fatty acid transport. PPAR $\alpha$ is involved in promoting gluconeogenesis (Xu et al. 2002) and stimulating hepatic fatty acid oxidation (Pawlak et al. 2015), which is the predominantly expressed form in the liver. It is worth noting that the treatment of adropin upregulated OA-inhibited PPAR $\alpha$ at the mRNA and protein levels in hepatocytes, which are thought to be involved in the increase in fatty acid oxidation in tilapia. This is contrary to the previous studies by Kumar et al. (2008) and Ganesh Kumar et al. (2012). In their studies, adropin overexpression or knockout mice could not affect hepatic PPAR $\alpha$ mRNA expression. The cause for this inconsistency is not readily apparent, but might be due to speciesspecific physiological differences. The enzyme of CPT1 $\alpha$ is essential for fatty acid oxidation (Bonnefont et al. 2004). However, this phenomenon is not supported by our results since Cpt1 $\alpha$ was not significantly different in this study. This is in agreement with the recent study by Thapa et al. (2019) where non-significant differences recorded in CPT1 $\alpha$ protein expression in adropin-treated high-fat diet mice. Therefore, adropin exhibits an inhibitory effect on hepatic lipid accumulation through the regulation of key lipid metabolic factors in a fish model.

Then we focused on the mechanism by which adropin modulated glucose utilization and triglyceride metabolism in OA-treated hepatocytes. The role of AMPK as a sensor of metabolism regulates glucose and lipid metabolism, which is a conserved master regulator of metabolism in vertebrates (Garcia \& Shaw 2017). Activation of AMPK has the potential to change cells from an anabolic to a catabolic state, leading to inhibition of hepatic lipogenesis and increased fatty acid oxidation 
(Kahn et al. 2005). AMPK could also modulate SREBP-1c and PPAR $\alpha$, which plays an important role in the regulation of gene products responsible for the synthesis of cholesterol, fatty acids, and triglycerides in the liver (Trepiana et al. 2018). These considerations prompted us to propose AMPK was likely to be targeted by adropin in OA-induced tilapia hepatocytes. However, it remains controversial whether AMPK is required for the metabolic effects of adropin. Some reports have demonstrated that adropin regulates cardiac energy substrate preference through activation of downstream insulin signalling, but not AMPK pathway (Altamimi et al. 2019). In line with this report, the administration of adropin fails to alter AMPK activity in the diet-induced obese male mice liver (Gao et al. 2019). In contrast, injection of adropin in the third ventricle of the rats increased AMPK activation via calmodulin-dependent protein kinase kinase- $\beta$ (Yang et al. 2017). In the present study, adropin treatment was found to activate AMPK to increase the p-AMPK/AMPK ratio in OA-treated hepatocytes. To further confirm whether the effects of adropin on glucose utilization and triglyceride metabolism were mediated by activation of AMPK, the pharmacological AMPK inhibitor compound-C and AMPK $\alpha 1$ siRNA were applied to block the AMPK signalling, respectively. We observed that blockade of adropin-induced activation of AMPK reversed its inhibition on SREBP-1c nuclear translocation. In addition, blocking AMPK also were effective in abolishing the inhibition of adropin on glucose output and triglyceride accumulation in hepatocytes. These data suggest that AMPK is required in adropin-induced gluconeogenesis and a marked accumulation of hepatic triglycerides in OA-induced fish hepatocytes. However, AMPK involved in adropin-induced glucose uptake can be ruled out because compound $\mathrm{C}$ had no effect on glucose uptake in hepatocytes. This result was surprising given that previous work in rodent models had shown

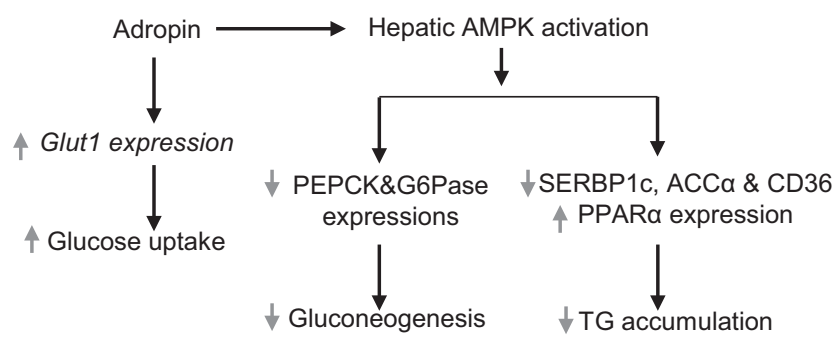

\section{Figure 8}

Schematic diagram showing the downstream signal mechanism of adropin in modulating glucose utilization and triglyceride (TG) accumulation in hepatocytes. Grey arrows represent the changes caused by adropin. that AMPK activation stimulates glucose uptake (Hayashi et al. 1998, Logie et al. 2018). Since adropin directly enhances the hepatic insulin signalling pathway to reduce hyperglycemia in diet-induced obesity mice (Gao et al. 2019), the possibility that adropin-stimulated glucose uptake activity through insulin signalling should be concerned. Together with these reports, our current findings suggest that adropin could activate AMPK and/or insulin signalling pathways under certain conditions. However, whether crosstalk was occurring between these two signalling pathways in the presence of adropin is still unclear. Therefore, studies are required to further elucidate how these two signalling pathways collectively contribute to the hypoglycemic effect of adropin.

In conclusion, our data demonstrate that tilapia adropin inhibits gluconeogenesis by downregulation of PEPCK and G6Pase enzyme activities and gene expression, and increases glucose uptake by upregulation of glut 1 gene expression. Meanwhile, adropin attenuates triglyceride accumulation by downregulating several important metabolic regulatory factors involved in lipid metabolism, such as SREBP-1c, ACC $\alpha$, and CD36 and upregulating PPAR $\alpha$ expression. We also propose that adropin activates AMPK to inhibit hepatic gluconeogenesis and triglyceride content in a high-fat environment (Fig. 8). Our results provide new knowledge of the adropin in Nile tilapia and could help to understand the regulatory mechanism of energy metabolism in fish.

\section{Supplementary materials}

This is linked to the online version of the paper at https://doi.org/10.1530/ JOE-20-0077.

\section{Declaration of interest}

The authors declare that there is no conflict of interest that could be perceived as prejudicing the impartiality of the research reported.

\section{Funding}

The project was supported by grants from the National Natural Science Foundation of China (31772824).

\section{References}

Akcilar R, Emel Kocak F, Simsek H, Akcilar A, Bayat Z, Ece E \& Kokdasgil H 2016 The effect of adropin on lipid and glucose metabolism in rats with hyperlipidemia. Iranian Journal of Basic Medical Sciences 19 245-251. https://joe.bioscientifica.com https://doi.org/10.1530/JOE-20-0077 (c) 2020 Society for Endocrinology Published by Bioscientifica Ltd. Printed in Great Britain 
Alegre M, Ciudad CJ, Fillat C \& Guinovart JJ 1988 Determination of glucose-6-phosphatase activity using the glucose dehydrogenasecoupled reaction. Analytical Biochemistry 173 185-189. (https://doi. org/10.1016/0003-2697(88)90176-5)

Altamimi TR, Gao S, Karwi QG, Fukushima A, Rawat S, Wagg CS, Zhang L \& Lopaschuk GD 2019 Adropin regulates cardiac energy metabolism and improves cardiac function and efficiency. Metabolism: Clinical and Experimental 98 37-48. (https://doi.org/10.1016/j.metabol.2019.06.005)

Bentle LA \& Lardy HA 1976 Interaction of anions and divalent metal ions with phosphoenolpyruvate carboxykinase. Journal of Biological Chemistry 251 2916-2921.

Bonnefont JP, Djouadi F, Prip-Buus C, Gobin S, Munnich A \& Bastin J 2004 Carnitine palmitoyltransferases 1 and 2: biochemical, molecular and medical aspects. Molecular Aspects of Medicine 25 495-520. (https://doi.org/10.1016/j.mam.2004.06.004)

Bougarne N, Weyers B, Desmet SJ, Deckers J, Ray DW, Staels B \& De Bosscher K 2018 Molecular actions of PPARalpha in lipid metabolism and inflammation. Endocrine Reviews 39 760-802. (https://doi. org/10.1210/er.2018-00064)

Butler AA, Tam CS, Stanhope KL, Wolfe BM, Ali MR, O'Keeffe M, St-Onge MP, Ravussin E \& Havel PJ 2012 Low circulating adropin concentrations with obesity and aging correlate with risk factors for metabolic disease and increase after gastric bypass surgery in humans. Journal of Clinical Endocrinology and Metabolism 97 3783-3791. (https://doi.org/10.1210/jc.2012-2194)

Ceddia RB 2013 The role of AMP-activated protein kinase in regulating white adipose tissue metabolism. Molecular and Cellular Endocrinology 366 194-203. (https://doi.org/10.1016/j.mce.2012.06.014)

Chen YJ, Zhang TY, Chen HY, Lin SM, Luo L \& Wang DS 2017 An evaluation of hepatic glucose metabolism at the transcription level for the omnivorous GIFT tilapia, Oreochromis niloticus during postprandial nutritional status transition from anabolism to catabolism. Aquaculture $\mathbf{4 7 3}$ 375-382. (https://doi.org/10.1016/j. aquaculture.2017.03.009)

Chen L, Duan Y, Wei H, Ning H, Bi C, Zhao Y, Qin Y \& Li Y 2019 Acetyl-CoA carboxylase (ACC) as a therapeutic target for metabolic syndrome and recent developments in ACC1/2 inhibitors. Expert Opinion on Investigational Drugs 28 917-930. (https://doi.org/10.1080/ 13543784.2019.1657825)

Chow BK, Moon TW, Hoo RL, Yeung CM, Muller M, Christos PJ \& Mojsov S 2004 Identification and characterization of a glucagon receptor from the goldfish Carassius auratus: implications for the evolution of the ligand specificity of glucagon receptors in vertebrates. Endocrinology 145 3273-3288. (https://doi.org/10.1210/en.2003-0597)

Du J, Jia R, Cao LP, Ding W, Xu P \& Yin G 2018 Effects of rhizoma Alismatis extract on biochemical indices and adipose gene expression in oleic acid-induced hepatocyte injury in Jian carp (Cyprinus carpio var. Jian). Fish Physiology and Biochemistry 44 747-768. (https://doi. org/10.1007/s10695-017-0428-2)

Folch J, Lees M \& Sloane Stanley GH 1957 A simple method for the isolation and purification of total lipides from animal tissues. Journal of Biological Chemistry 226 497-509.

Foretz M, Pacot C, Dugail I, Lemarchand P, Guichard C, Le Liepvre X, Berthelier-Lubrano C, Spiegelman B, Kim JB, Ferre P, et al. 1999 $\mathrm{ADD} 1 / \mathrm{SREBP}-1 \mathrm{c}$ is required in the activation of hepatic lipogenic gene expression by glucose. Molecular and Cellular Biology 19 3760-3768. (https://doi.org/10.1128/mcb.19.5.3760)

Fujii T, Ha H, Yokoyama H, Hamamoto H, Yoon SH \& Hori H 1995 Applications of MTT assay to primary cultured rat hepatocytes. Biological and Pharmaceutical Bulletin 18 1446-1449. (https://doi. org/10.1248/bpb.18.1446)

Ganesh Kumar K, Zhang J, Gao S, Rossi J, McGuinness OP, Halem HH, Culler MD, Mynatt RL \& Butler AA 2012 Adropin deficiency is associated with increased adiposity and insulin resistance. Obesity 20 1394-1402. (https://doi.org/10.1038/oby.2012.31)
Gao S, McMillan RP, Zhu Q, Lopaschuk GD, Hulver MW \& Butler AA 2015 Therapeutic effects of adropin on glucose tolerance and substrate utilization in diet-induced obese mice with insulin resistance. Molecular Metabolism 4 310-324. (https://doi.org/10.1016/j.molmet.2015.01.005)

Gao S, Ghoshal S, Zhang L, Stevens JR, McCommis KS, Finck BN, Lopaschuk GD \& Butler AA 2019 The peptide hormone adropin regulates signal transduction pathways controlling hepatic glucose metabolism in a mouse model of diet-induced obesity. Journal of Biological Chemistry 294 13366-13377. (https://doi.org/10.1074/jbc. RA119.008967)

Garcia D \& Shaw RJ 2017 AMPK: mechanisms of cellular energy sensing and restoration of metabolic balance. Molecular Cell 66 789-800. (https://doi.org/10.1016/j.molcel.2017.05.032)

Garcia NA, Gonzalez-King H, Grueso E, Sanchez R, Martinez-Romero A, Javega B, O'Connor JE, Simons PJ, Handberg A \& Sepulveda P 2019 Circulating exosomes deliver free fatty acids from the bloodstream to cardiac cells: possible role of CD36. PLOS ONE 14 e0217546. (https:// doi.org/10.1371/journal.pone.0217546)

Ghoshal S, Stevens JR, Billon C, Girardet C, Sitaula S, Leon AS, Rao DC, Skinner JS, Rankinen T, Bouchard C, et al. 2018 Adropin: an endocrine link between the biological clock and cholesterol homeostasis. Molecular Metabolism 8 51-64. (https://doi.org/10.1016/j. molmet.2017.12.002)

Hayashi T, Hirshman MF, Kurth EJ, Winder WW \& Goodyear LJ 1998 Evidence for 5' AMP-activated protein kinase mediation of the effect of muscle contraction on glucose transport. Diabetes 47 1369-1373. (https://doi.org/10.2337/diab.47.8.1369)

He AY, Ning LJ, Chen LQ, Chen YL, Xing Q, Li JM, Qiao F, Li DL, Zhang ML \& Du ZY 2015 Systemic adaptation of lipid metabolism in response to low- and high-fat diet in Nile tilapia (Oreochromis niloticus). Physiological Reports 3 e12485. (https://doi.org/10.14814/phy2.12485)

Horton JD, Goldstein JL \& Brown MS 2002 SREBPs: activators of the complete program of cholesterol and fatty acid synthesis in the liver. Journal of Clinical Investigation 109 1125-1131. (https://doi. org/10.1172/JCI15593)

Jasaszwili M, Billert M, Strowski MZ, Nowak KW \& Skrzypski M 2020 Adropin as A fat-burning hormone with multiple functions-review of a decade of research. Molecules 25 549. (https://doi.org/10.3390/ molecules25030549)

Jiang Q \& Wong AO 2013 Signal transduction mechanisms for autocrine/ paracrine regulation of somatolactin-alpha secretion and synthesis in carp pituitary cells by somatolactin-alpha and -beta. American Journal of Physiology: Endocrinology and Metabolism 304 E176-E186. (https:// doi.org/10.1152/ajpendo.00455.2012)

Kahn BB, Alquier T, Carling D \& Hardie DG 2005 AMP-activated protein kinase: ancient energy gauge provides clues to modern understanding of metabolism. Cell Metabolism 1 15-25. (https://doi.org/10.1016/j. cmet.2004.12.003)

Karim S, Adams DH \& Lalor PF 2012 Hepatic expression and cellular distribution of the glucose transporter family. World Journal of Gastroenterology 18 6771-6781. (https://doi.org/10.3748/wjg.v18. i46.6771)

Kumar KG, Trevaskis JL, Lam DD, Sutton GM, Koza RA, Chouljenko VN, Kousoulas KG, Rogers PM, Kesterson RA, Thearle M, et al. 2008 Identification of adropin as a secreted factor linking dietary macronutrient intake with energy homeostasis and lipid metabolism. Cell Metabolism 8 468-481. (https://doi.org/10.1016/j.cmet.2008.10.011)

Lian A, Wu K, Liu T, Jiang N \& Jiang Q 2016 Adropin induction of lipoprotein lipase expression in tilapia hepatocytes. Journal of Molecular Endocrinology 56 11-22. (https://doi.org/10.1530/JME-15-0207)

Liu HY, Collins QF, Xiong Y, Moukdar F, Lupo Jr EG, Liu Z \& Cao W 2007 Prolonged treatment of primary hepatocytes with oleate induces insulin resistance through p38 mitogen-activated protein kinase. Journal of Biological Chemistry 282 14205-14212. (https://doi. org/10.1074/jbc.M609701200) https://joe.bioscientifica.com

https://doi.org/10.1530/JOE-20-0077 (c) 2020 Society for Endocrinology Published by Bioscientifica Ltd. Printed in Great Britain 
Liu H, Xu Y, Wang Y, Zhong S, Wang M, Lin P, Li H \& Liu Z 2017 CD36 is a candidate lipid sensor involved in the sensory detection of fatty acid in zebrafish. Physiology and Behavior 182 34-39. (https://doi. org/10.1016/j.physbeh.2017.09.015)

Liu L, Wang Q, Wang Q, Zhao X, Zhao P, Geng T \& Gong D 2018 Role of miR29c in goose fatty liver is mediated by its target genes that are involved in energy homeostasis and cell growth. BMC Veterinary Research 14 325. (https://doi.org/10.1186/s12917-018-1653-3)

Logie L, Lees Z, Allwood JW, McDougall G, Beall C \& Rena G 2018 Regulation of hepatic glucose production and AMPK by AICAR but not by metformin depends on drug uptake through the equilibrative nucleoside transporter 1 (ENT1). Diabetes, Obesity and Metabolism 20 2748-2758. (https://doi.org/10.1111/dom.13455)

Malhi H, Bronk SF, Werneburg NW \& Gores GJ 2006 Free fatty acids induce JNK-dependent hepatocyte lipoapoptosis. Journal of Biological Chemistry 281 12093-12101. (https://doi.org/10.1074/jbc. M510660200)

Mao J, DeMayo FJ, Li H, Abu-Elheiga L, Gu Z, Shaikenov TE, Kordari P, Chirala SS, Heird WC \& Wakil SJ 2006 Liver-specific deletion of acetyl-CoA carboxylase 1 reduces hepatic triglyceride accumulation without affecting glucose homeostasis. PNAS 103 8552-8557. (https://doi.org/10.1073/pnas.0603115103)

Mencarelli A, Cipriani S, Renga B, Francisci D, Palladino G, Distrutti E, Baldelli F \& Fiorucci S 2010 The bile acid sensor FXR protects against dyslipidemia and aortic plaques development induced by the HIV protease inhibitor ritonavir in mice. PLOS ONE 5 e13238. (https://doi. org/10.1371/journal.pone.0013238)

Miquilena-Colina ME, Lima-Cabello E, Sanchez-Campos S, GarciaMediavilla MV, Fernandez-Bermejo M, Lozano-Rodriguez T, VargasCastrillon J, Buque X, Ochoa B, Aspichueta P, et al. 2011 Hepatic fatty acid translocase CD36 upregulation is associated with insulin resistance, hyperinsulinaemia and increased steatosis in non-alcoholic steatohepatitis and chronic hepatitis C. Gut 60 1394-1402. (https:// doi.org/10.1136/gut.2010.222844)

Ning LJ, He AY, Lu DL, Li JM, Qiao F, Li DL, Zhang ML, Chen LQ \& Du ZY 2017 Nutritional background changes the hypolipidemic effects of fenofibrate in Nile tilapia (Oreochromis niloticus). Scientific Reports 7 41706. (https://doi.org/10.1038/srep41706)

Ochs RS \& Harris RA 1986 Mechanism for the oleate stimulation of gluconeogenesis from dihydroxyacetone by hepatocytes from fasted rats. Biochimica et Biophysica Acta $\mathbf{8 8 6}$ 40-47. (https://doi. org/10.1016/0167-4889(86)90209-0)

Oliveira AF, Cunha DA, Ladriere L, Igoillo-Esteve M, Bugliani M, Marchetti P \& Cnop M 2015 In vitro use of free fatty acids bound to albumin: a comparison of protocols. BioTechniques $\mathbf{5 8} 228-233$ (https://doi.org/10.2144/000114285)

Pawlak M, Lefebvre P \& Staels B 2015 Molecular mechanism of PPARalpha action and its impact on lipid metabolism, inflammation and fibrosis in non-alcoholic fatty liver disease. Journal of Hepatology 62 720-733. (https://doi.org/10.1016/j.jhep.2014.10.039)

Rao A \& Herr DR 2017 G Protein-coupled receptor GPR19 regulates E-cadherin expression and invasion of breast cancer cells. Biochimica et Biophysica Acta: Molecular Cell Research 1864 1318-1327. (https:// doi.org/10.1016/j.bbamcr.2017.05.001)

Rui L 2014 Energy metabolism in the liver. Comprehensive Physiology 4 177-197. (https://doi.org/10.1002/cphy.c130024)

Sharma S, Mells JE, Fu PP, Saxena NK \& Anania FA 2011 GLP-1 analogs reduce hepatocyte steatosis and improve survival by enhancing the unfolded protein response and promoting macroautophagy. PLoS ONE 6 e25269. (https://doi.org/10.1371/journal.pone.0025269)
Shi HJ, Xu C, Liu MY, Wang BK, Liu WB, Chen DH, Zhang L, Xu CY \& Li XF 2018 Resveratrol improves the energy sensing and glycolipid metabolism of blunt snout bream megalobrama amblycephala fed high-carbohydrate diets by activating the AMPK-SIRT1-PGC-1alpha network. Frontiers in Physiology 9 1258. (https://doi.org/10.3389/ fphys.2018.01258)

Stein LM, Yosten GL \& Samson WK 2016 Adropin acts in brain to inhibit water drinking: potential interaction with the orphan $G$ proteincoupled receptor, GPR19. American Journal of Physiology: Regulatory, Integrative and Comparative Physiology 310 R476-R480. (https://doi. org/10.1152/ajpregu.00511.2015)

Stubhaug I, Tocher DR, Bell JG, Dick JR \& Torstensen BE 2005 Fatty acid metabolism in Atlantic salmon (Salmo salar L.) hepatocytes and influence of dietary vegetable oil. Biochimica et Biophysica Acta 1734 277-288. (https://doi.org/10.1016/j.bbalip.2005.04.003)

Talukdar S \& Hillgartner FB 2006 The mechanism mediating the activation of acetyl-coenzyme A carboxylase-alpha gene transcription by the liver X receptor agonist T0-901317. Journal of Lipid Research 47 2451-2461. (https://doi.org/10.1194/jlr.M600276-JLR200)

Thapa D, Stoner MW, Zhang M, Xie B, Manning JR, Guimaraes D, Shiva S, Jurczak MJ \& Scott I 2018 Adropin regulates pyruvate dehydrogenase in cardiac cells via a novel GPCR-MAPK-PDK4 signaling pathway. Redox Biology 18 25-32. (https://doi.org/10.1016/j. redox.2018.06.003)

Thapa D, Xie B, Manning JR, Zhang M, Stoner MW, Huckestein BR, Edmunds LR, Zhang X, Dedousis NL, O'Doherty RM, et al. 2019 Adropin reduces blood glucose levels in mice by limiting hepatic glucose production. Physiological Reports 7 e14043. (https://doi. org/10.14814/phy2.14043)

Trepiana J, Milton-Laskibar I, Gomez-Zorita S, Eseberri I, Gonzalez M, Fernandez-Quintela A \& Portillo MP 2018 Involvement of 5'-activated protein kinase (AMPK) in the effects of resveratrol on liver steatosis. International Journal of Molecular Sciences 19 3473. (https://doi. org/10.3390/ijms19113473)

Wilson CG, Tran JL, Erion DM, Vera NB, Febbraio M \& Weiss EJ 2016 Hepatocyte-specific disruption of CD36 attenuates fatty liver and improves insulin sensitivity in HFD-Fed Mice. Endocrinology 157 570-585. (https://doi.org/10.1210/en.2015-1866)

Wolf K 1963 Physiological salines for fresh-water teleosts. Progressive Fish-Culturist 25 135-140. (https://doi.org/10.1577/15488659(1963)25[135:PSFFT]2.0.CO;2)

Xu J, Xiao G, Trujillo C, Chang V, Blanco L, Joseph SB, Bassilian S, Saad MF, Tontonoz P, Lee WN, et al. 2002 Peroxisome proliferatoractivated receptor alpha (PPARalpha) influences substrate utilization for hepatic glucose production. Journal of Biological Chemistry 277 50237-50244. (https://doi.org/10.1074/jbc.M201208200)

Yabaluri N \& Bashyam MD 2010 Hormonal regulation of gluconeogenic gene transcription in the liver. Journal of Biosciences 35 473-484. (https://doi.org/10.1007/s12038-010-0052-0)

Yang F, Zhou L, Qian X, Wang D, He WJ, Tang ZW, Yin J \& Huang QY 2017 Adropin is a key mediator of hypoxia induced anti-dipsogenic effects via TRPV4-CamKK-AMPK signaling in the circumventricular organs of rats. Frontiers in Molecular Neuroscience 10 105. (https://doi. $\operatorname{org} / 10.3389 /$ fnmol.2017.00105)

Yanhong F, Chenghua H, Guofang L \& Haibin Z 2008 Optimization of the isolation and cultivation of Cyprinus carpio primary hepatocytes. Cytotechnology 58 85-92. (https://doi.org/10.1007/s10616-008-9169-5)

Zimmerman AW \& Veerkamp JH 2002 New insights into the structure and function of fatty acid-binding proteins. Cellular and Molecular Life Sciences 59 1096-1116. (https://doi.org/10.1007/s00018-002-8490-y)

Received in final form 28 April 2020

Accepted 19 May 2020

Accepted Manuscript published online 19 May 2020 https://joe.bioscientifica.com https://doi.org/10.1530/JOE-20-0077 (c) 2020 Society for Endocrinology Published by Bioscientifica Ltd. Printed in Great Britain 